\title{
Restoring the soul
}

\author{
Walker M. Blanding, BS, and Chadrick E. Denlinger, MD
}

From the Division of Cardiothoracic Surgery, Medical University of South Carolina, Charleston, SC.

Disclosures: Authors have nothing to disclose with regard to commercial support.

Received for publication April 5, 2018; accepted for publication April 9, 2018; available ahead of print May 2, 2018.

Address for reprints: Chadrick E. Denlinger, MD, Division of Cardiothoracic Surgery, Department of Surgery,

Medical University of South Carolina, 114 Doughty St, Charleston, SC 29425 (E-mail: denlinge@musc.edu).

J Thorac Cardiovasc Surg 2018;156:836-7

$0022-5223 / \$ 36.00$

Copyright (c) 2018 by The American Association for Thoracic Surgery

https://doi.org/10.1016/j.jtcvs.2018.04.032

Chyle was once described to me as synonymous with a patient's soul. Watching a chest tube drain $1500 \mathrm{~mL}$ of chyle a day is not only demoralizing, but it quite literally sucks the life out of patients. Invariably, they are tachycardic, listless, and prone to further complications. Furthermore, these symptoms seem out of proportion to the observed volume loss and nutritional depletion. Thus, a fitting analogy is that the patient's soul is slowly but persistently being drained from their body as the chyle leak continues day after day. In the same way, correction of a chyle leak rapidly restores the patient's feeling of well-being and favorable outlook on life.

Treatment of this serious condition has evolved over the past 3 decades. Conservative management includes dietary modifications ranging from a medium chain fatty acid diet to complete cessation or enteral nutrition and the addition of somatostatin analogs. Following failed medical therapy, surgical treatment through ligation of the thoracic duct with or without pleurodesis offers a meager success rate of $70 \%$, and thus, the chyle leak drains the soul of the patient and the surgical team as well. ${ }^{1}$ Embryonic variation, collaterals, and missed ligation because of the difficulty visualizing the source of clear fluid trickling from deep in the chest at a rate of $1 \mathrm{~mL} / \mathrm{min}$ contribute to surgical failures. Visualization can be enhanced by providing enteral cream several hours before operative exploration, but even this adjunct is not entirely reliable.

Nadolski and Itkin $^{2}$ report their success with lymphangiography-guided thoracic duct embolization in 50 patients who previously failed surgical ligation. First described by Cope in 5 patients in $1998^{3}$ and again in 42 patients in $2002,{ }^{4}$ techniques consist of percutaneous catheterization of the cisterna chyli after pedal or intranodal lymphangiography with subsequent deployment of coils, embolic material, and/or sclerosing agents into the thoracic duct. Unlike Cope's work, Nadolski and Itkin's cohort had already failed surgical ligation, yet, the success rates was still $90 \%$, with only a $6 \%$ minor complication rate. Itkin and colleagues ${ }^{5}$ have reported on a cohort of 109 patients, showing a similar $90 \%$ success rate for those in whom

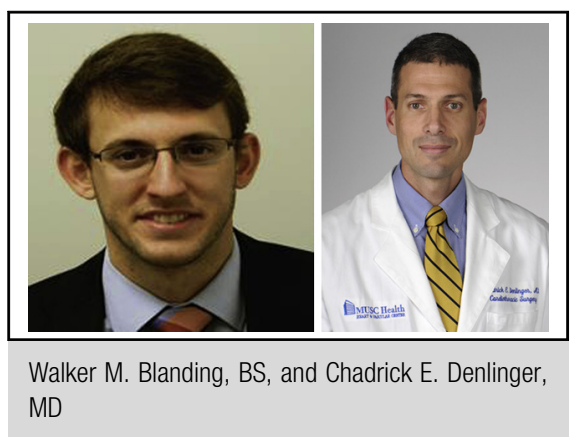

\section{Central Message}

Percutaneous lymphangiography and thoracic duct embolization offers another tool for treatment of intrathoracic chylous leak in traumatic and nontraumatic etiologies.

See Article page 838

embolization could be achieved and $72 \%$ success rate for needle interruption with failed embolization. In this series, only $18 \%$ had previously undergone surgical ligation attempts.

Interestingly, Nadolski and Itkin ${ }^{2}$ showed that the majority of patients who failed initial ligation suffered from missed or incomplete duct ligation, thus identifying a population in which subsequent surgical ligation attempts may be successful. Alternatively, $30 \%$ of patients had collaterals presumably not amenable to primary or secondary attempts. Perhaps embolization attempts may be more efficacious than surgical ligation as the primary approach in centers in which interventional radiologists are both capable and willing. If embolization fails, subsequent ligation could be guided by images of ductal and collateral anatomy. In either case, percutaneous embolization provides an effective tool for controlling chyle leaks when wielded by experienced hands. We need to re-evaluate the most effective means of restoring the soul of a tired and listless patient population suffering from persistent chyle leaks.

\section{References}

1. Shah RD, Luketich JD, Schuchert MJ, Christie NA, Pennathur A, Landreneau RJ, et al. Postesophajectomy chylothorax, risk factors and outcomes. Ann Thorac Surg. 2012;93:897-904.

2. Nadolski GJ, Itkin M. Lymphangiography and thoracic duct embolization following unsuccessful thoracic duct ligation: imaging findings and outcomes. $J$ Thorac Cardiovasc Surg. 2018;156:838-43.

3. Cope C. Diagnosis and treatment of postoperative chyle leakage via percutaneous transabdominal catheterization of the cisterna chyli: a preliminary study. J Vasc Interv Radiol. 1998;9:727-34. 
4. Cope C, Kaiser LR. Management of unremitting chylothorax by percutaneous embolization and blockage of retroperitoneal lymphatic vessels in 42 patients. $J$ Vasc Interv Radiol. 2002;13:1139-48.
5. Itkin M, Kucharczuk JC, Kwak A, Trerotola SO, Kaiser LR. Nonoperativce thoracic duct embolization for traumatic thoracic duct leak: experience in $109 \mathrm{pa}-$ tients. J Thorac Cardiovasc Surg. 2010;139:584-90. 